\title{
Causes of Admissions and Deaths in Neonate Department Benghazi Children Hospital 2019
}

\author{
Dr. Mohamed Masoud Alferjani ${ }^{1 *}$, Dr. Fatema Alsedawi ${ }^{2}$, Dr. Salema Alzhawi ${ }^{3}$, Dr. Fadwa Abdalhamid Aldeghaily ${ }^{2}$
}

\author{
${ }^{1}$ Assistant Professor, Consultant Neonatology and Genetics- Benghazi Children Hospital, Garyounis University, Benghazi, Libya \\ ${ }^{2}$ Lecturer, Consultant Neonatology Benghazi Children Hospital, Garyounis University, Benghazi, Libya \\ ${ }^{3}$ Lecturer, Consultant Pediatric Department, Garyounis University, Benghazi, Libya
}

DOI: $10.36347 /$ sjams.2022.v10i01.019

| Received: 11.12.2021 | Accepted: 15.01.2022 | Published: 24.01.2022

*Corresponding author: Dr. Mohamed Masoud Alferjani

Assistant Professor, Consultant Neonatology and Genetics-Benghazi Children Hospital, Garyounis University, Benghazi, Libya

\section{Abstract}

\section{Original Research Article}

This research aims to study the causes of neonatal admissions and deaths among newborns at neonate department in Benghazi Children Hospital. A cross sectional retrospective study was conducted during 2019. Data included; causes of admission, causes of deaths, gender, age, residency, area of referral, duration of hospital stay. Out of 1720 neonatal admissions reviewed, the total number of deaths was 229 , the overall mortality rate was $(13.3 \%)$ but much higher (25.2\%) among the referred babies. The male gender was predominant admissions and deaths $(61.3 \%$ and $63 \%$ respectively). Most of neonatal admissions and deaths were occurred in the first week of life. The most frequent cause of admission was neonatal jaundice 492 (28.6\%) followed by RD $380(22.1 \%)$. The common cause of death was prematurity and its related problems $66(28.3 \%)$, then neonatal sepsis $51(22.3 \%)$ and congenital heart disease $36(15.7 \%)$.

Keywords: Neonate Department, neonatal admissions, wellbeing, death.

Copyright $(9) 2022$ The Author(s): This is an open-access article distributed under the terms of the Creative Commons Attribution 4.0 International License (CC BY-NC 4.0) which permits unrestricted use, distribution, and reproduction in any medium for non-commercial use provided the original author and source are credited.

\section{BACKGROUND}

He first month is the most crucial period for child survival. Neonatal mortality continues to remain high with little improvement over the years in SubSaharan Africa, and North Africa including Libya.

This regions shows the least progress in reducing neonatal mortality and continues to be a significant public health issue.

The causes and predictors of neonatal admissions and deaths in the neonatal intensive care unit are not well documented.

Hence, this study aimed to determine the causes and predictors of neonatal admissions and mortality among infants admitted to neonatal department in Benghazi children hospital

The neonatal period is a highly vulnerable period of life when a neonate may develop certain serious problems which lead to death) [1].
Neonatal mortality is highest in the first 24 hours of life and accounts for $65 \%$ of infant mortality [2].

The neonatal mortality rate is the number of neonates dying before reaching 28 days of age, per 1,000 live births in a given year [3], is a core indicator for neonatal health and wellbeing and is becoming a prominent component of overall under-five mortality. It is therefore receiving particular attention from Health authorities 1 .

Even though the under-5 mortality rate dropped by $47 \%$ (from 9.9 million to 5.6 million children) from 2000 to 2016 globally, the neonatal mortality rate only fell by $39 \%$ over the same period [2].

Of the 5.9 million under five deaths reported in 2015, 2.7 million died during the neonatal period [3]

A World Health Organization (WHO) report stated that worldwide neonatal mortality rates decreased from 36 deaths per 1,000 live births in 1990 to 19 cases 
per 1,000 live births in 2015 , which indicates that the neonatal mortality rate has fallen by 45 to $47 \%$ during these years.

In 2017, UNICEF reported that neonatal mortality from sub-Saharan Africa and South Asia, accounted for 27/1000 live births. A child born from this region was nine times more likely to die in the first month of life than a child from a high-income country (https://data.unicef.org/topic/child-survival/neonatalmortality/).
A number of previous studies have attempted to identify factors associated with neonatal admission [4] and mortality whilst there was only $2.8 \%$ reduction for Africa and $2.9 \%$ for sub-Saharan Africa over the same period $[4,5]$.

Therefore, this study was designed to evaluate neonatal mortality and associated factors among newborns admitted to the Specialized Neonatal Care Unit (SNCU) (Neonatal department) in Benghazi children hospital 2019.

\section{Distribution of under-five deaths by age-groups}

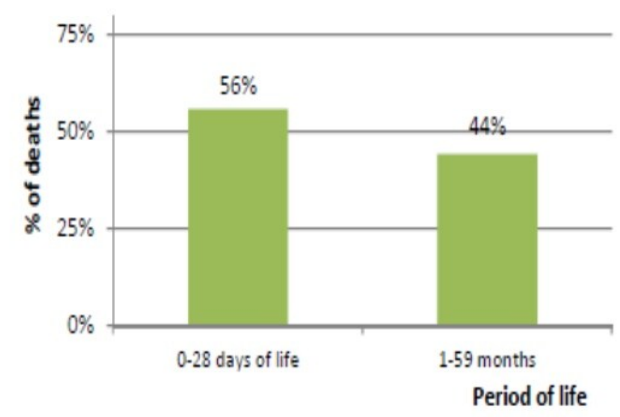

Source:Calculated based on data from the UNICEF/WHO/The World Bank/UN Pop Div. Levels and Trends in Child Mortality Report 2014

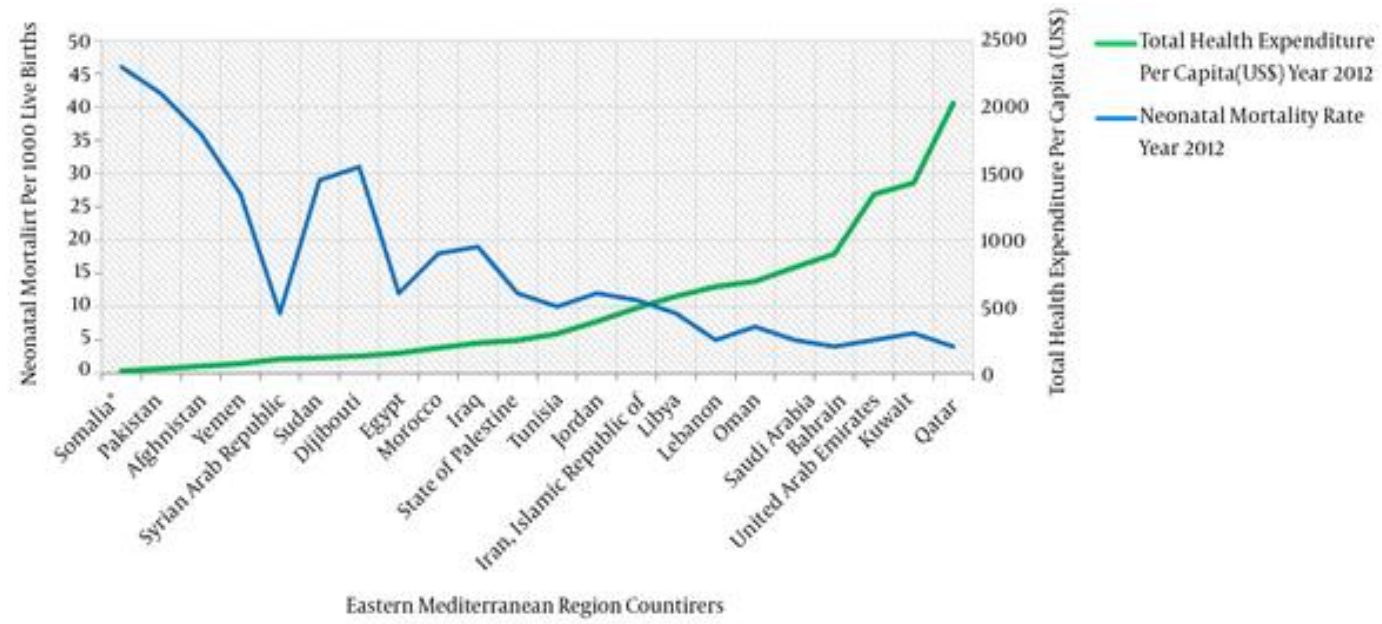

\section{Common causes of neonatal mortalities}

1. Prematurity: Premature infants come early into the world, and they are born fragile, small, and weighing less than full term infants. Many of the babies who survive face greater risks of significant health problems and disability throughout their lives (I.e. learning disabilities, visual and hearing problems, chronic lung disease and other long-term diseases).

2. Neonatal infections: Neonatal infections are a major cause of death worldwide. It is estimated that approximately 4 million deaths occur annually in developing countries in the neonatal period.

3. Birth Asphyxia: It is estimated that in developing countries, asphyxia causes around seven deaths per 1000 births, whereas in developed countries, this proportion is less than one death per 1000 births.

4. Respiratory Distress Syndrome (RDS) or Hyaline Membrane Disease (HMD): RDS is one of the most common causes of neonatal respiratory failure. According to the National Neonatal Perinatal Database 2003, HMD was found to affect 
$1.2 \%$ of total live births and contributed to $13.5 \%$ of total neonatal deaths.

5. Congenital anomalies: Congenital malformation such as congenital heart diseases

\section{ОВJECTIVE}

- To determine causes of neonatal admissions ,neonatal deaths ,neonatal mortality rate, and associated factors in the Neonatal Department in Benghazi children hospital

- To evaluate the causes of transfer and deaths in referred cases

\section{Methods and Study design}

A retrospective cross-sectional study was carried out to investigate neonatal admissions, mortality and associated factors among neonates admitted to the neonatal department in Benghazi children hospital in 2019.

\section{METHODS}

Medical records of all neonates admitted to the Neonatal Care Unit at the period from 1 January 2019 to 31 December 2019 were reviewed using a crosssectional study. Data included; causes of admission, causes of deaths, gender, age, residency, area of referral and duration of hospital stay was collected.

- The neonatal department in Benghazi children hospital provides services to newborns born in Benghazi and surrounding areas and it is a referral center to most of eastern Libyan part.

- $\quad$ The department has about 60 incubators ,30 cots, 710 ventilator machines

- $\quad$ The quality of man power inside the unit over 24 hours was divided into two shifts, each shift included 3-4 doctors ( $\mathrm{SHO}$ ), one senior registrar and one in call consultant and 4 nurses.

- The average daily admissions is 4.77 cases

Benghazi children hospital

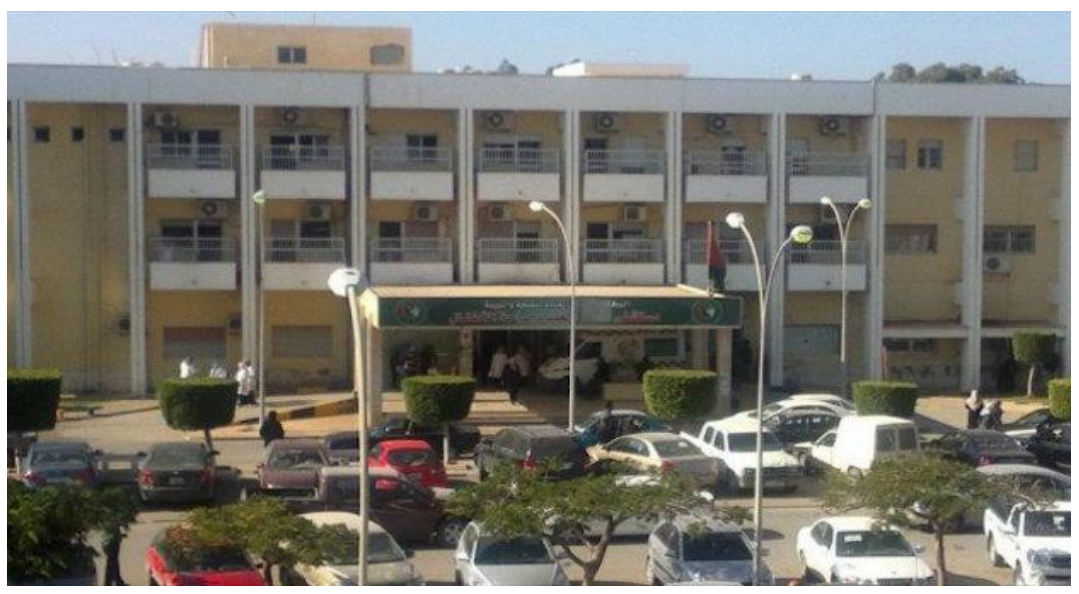

The most important causes of admission and mortality were analyzed. Univariate and multivariate logistic regression analysis was used to evaluate the causes and risk factors associated with neonatal mortality. Variables significant at $\mathrm{P}<0.05$ level in the Model fit was evaluated using Chi-square $=12.89$, df $=$ $8 ; \mathrm{P}=0.116$ ), implies the model's estimates fit the data at an acceptable level.. P-value $<0.05$ was considered statistically significant.

\section{Study Population}

Information of all the 1720 , males $(n=1055$, $61.33 \%)$ and female $(n=665,38.66 \%)$ neonates admitted to the NCU from January 1st -December 31st, 2019 was reviewed, with complete information were included in the study.

\section{Statistical analysis}

- Double data input was performed using CSPro (version-7) software, and was exported to SPSS statistical package version 20 for windows (SPSS) for analysis.
- Quantitative indices are expressed as means \pm standard deviations using t-test. were significant at $\mathrm{P}$ value of $<0.05$ level in the univariate analysis were included and retained in the multivariate model.

- We evaluated model fit through inspection of Hosmer and Lemeshow test (Chi-square $=12.89$, df $=8 ; \mathrm{P}=0.116)$, which implies that the model's estimates fit the data at an acceptable level.

- Ethical approval was sought out from the Ministry of Health research ethics and protocol review committee.

\section{Causes of admission in to NICU}

As elsewhere, jaundice was the major cause 492 (28.6\%) of admission, followed by Respiratory distress (RDS, TTN, MAS, Pneumonia, pneumothorax.. etc.) $380(22.1 \%)$, prematurity $270(15.7 \%)$, sepsis 264(15.3). Congenital abnormality, including neural tube defect, digestive tract obstruction, multiple congenital anomalies 30(1.74\%), congenital heart disease 29(1.68\%), and Downs syndrome 15(0.87\%), neonatal convulsions 34(1.97\%), birth asphyxia

116


$15(0.87 \%)$ were among the commonly reported neonatal disorders and Infants of diabetic mothers (IDM) 23(1.33\%)

Causes of neonatal deaths

- From the total admissions of 1720, 229 babies died in 2019 in the NICU.

- Preterm births with its complications were the major causes of neonatal mortality and accounted the highest $(\mathrm{n}=66,28.8 \%)$ cause of mortality followed by sepsis $(\mathrm{n}=51,22.3 \%)$, congenital heart disease $(\mathrm{n}=36,15.7 \%)$, congenital anomalies $18(7.86 \%)$, metabolic diseases $15(6.55 \%)$ and birth asphyxia $12(5.24 \%)$.

- Overall neonatal mortality in the NCUI was $13.3 \%$. There was a significant association between prematurity (< 37 weeks), and mortality $(\mathrm{P}<$ $0.001)$ also neonatal sepsis and mortality

\section{RESULTS}

As elsewhere, jaundice was the major cause $492(28.6 \%)$ of admission, followed by respiratory problems $380(20.1 \%)$, prematurity $270(20.3 \%)$, sepsis $264(15.3 \%)$ and congenital heart diseases $80(4.7 \%)$.

Most of the admitted baby stayed 1 to 10 days. The proportion of facility-based neonatal mortality was $13.31 \%$. 144(62.9\%) males and $85(37.1 \%)$ females.

The causes of death were prematurity and associated complications $(n=66,28.8 \%)$. sepsis $(n=$ $51,22.3 \%)$, and congenital malformation including congenital heart diseases $(20.9 \%)$, metabolic diseases $(n=15,6.55 \%)$ birth asphyxia $(n=12,5.24 \%)$.

The incidence of deaths is much higher in referred cases $(25.2 \%)$ in comparison with death of cases came from home $(8.1 \%)$.

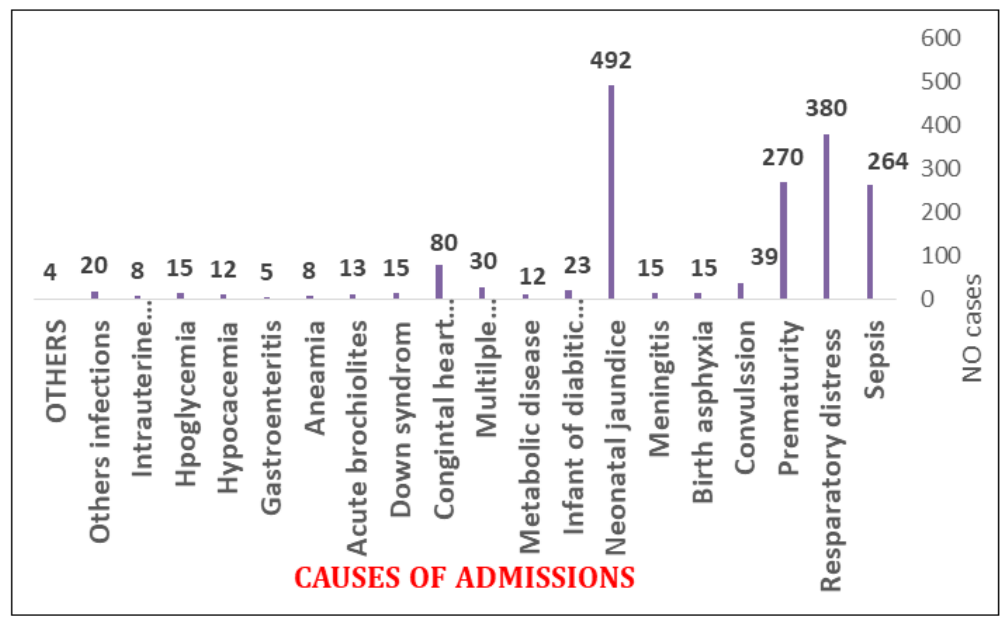

Total admissions and gender distribution 2019

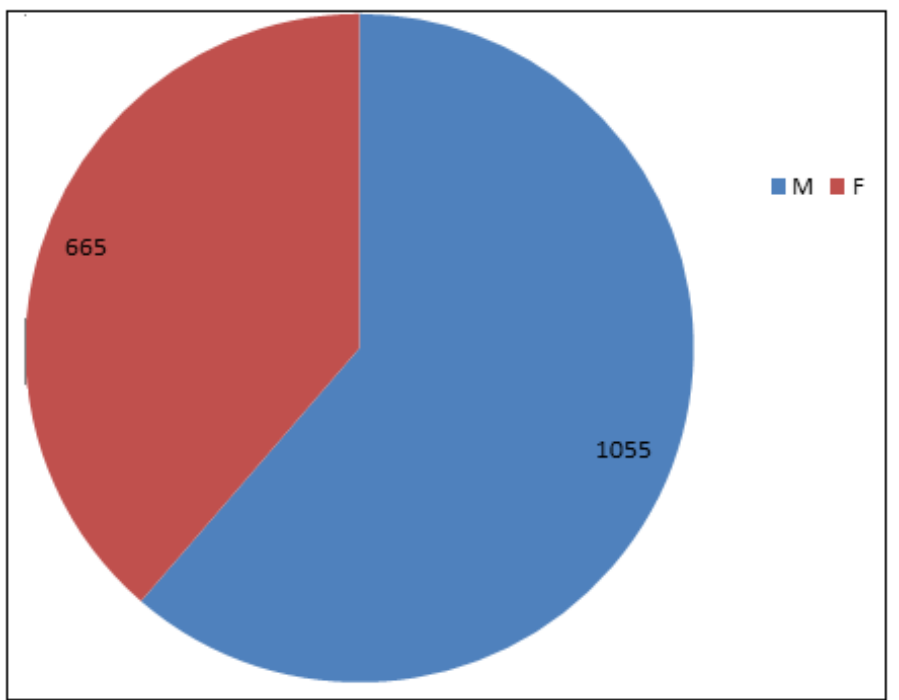




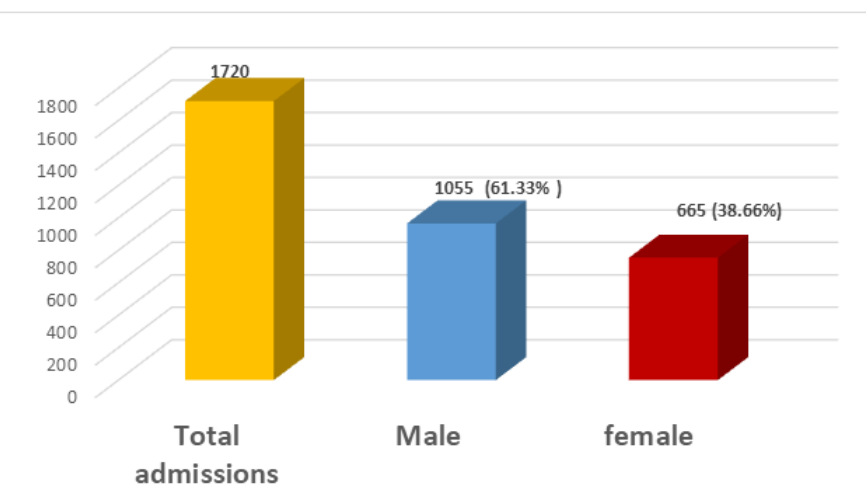

Admissions according to age distribution

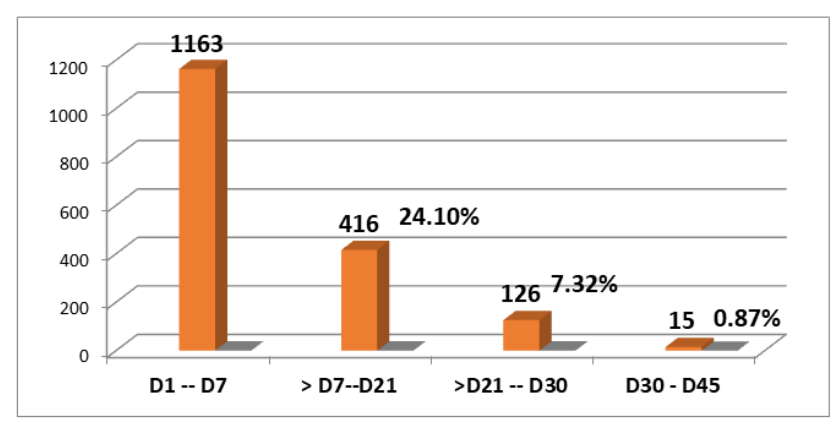

Admissions according to residence

\begin{tabular}{|l|l|l|}
\hline city & No of cases & percent \\
\hline Benghazi & 1621 & $\mathbf{9 4 . 2 4 \%}$ \\
\hline Darna & 8 & $\mathbf{0 . 4 6 \%}$ \\
\hline Tobrouk & 7 & $\mathbf{0 . 4 0 \%}$ \\
\hline Ejdabia & 27 & $\mathbf{1 . 5 7 \%}$ \\
\hline Albeda & 10 & $\mathbf{0 . 5 8 \%}$ \\
\hline Almaraj & 15 & $\mathbf{0 . 8 7 \%}$ \\
\hline alkofra & 5 & $\mathbf{0 . 2 9 \%}$ \\
\hline Jalo & 3 & $\mathbf{0 . 1 7 \%}$ \\
\hline Sabha & 2 & $\mathbf{0 . 1 2 \%}$ \\
\hline Saloog & 5 & $\mathbf{0 . 2 9 \%}$ \\
\hline Alabiar & 9 & $\mathbf{0 . 5 2 \%}$ \\
\hline Marada & 2 & $\mathbf{0 . 1 2 \%}$ \\
\hline Seret & 6 & $\mathbf{0 . 3 5 \%}$ \\
\hline
\end{tabular}

\section{Admissions from Benghazi and outside Benghazi}

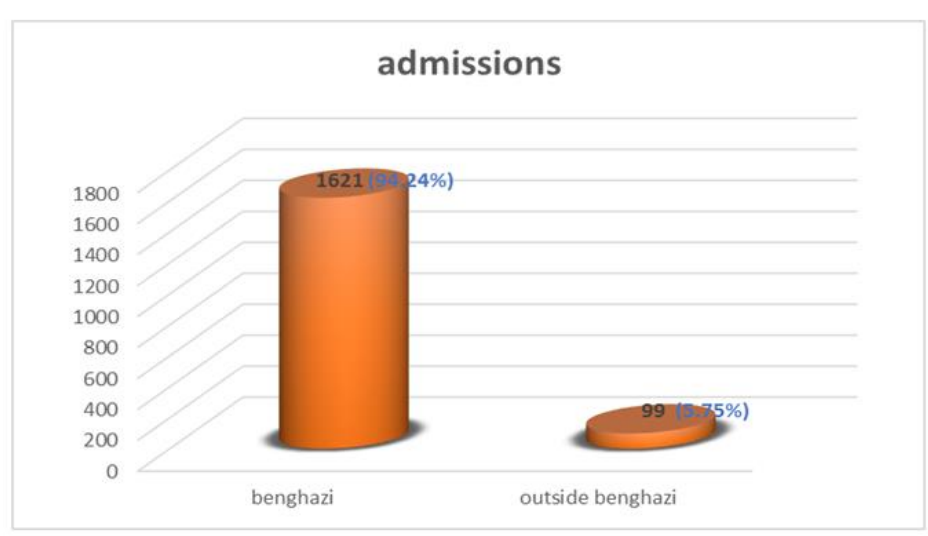

Causes of deaths 

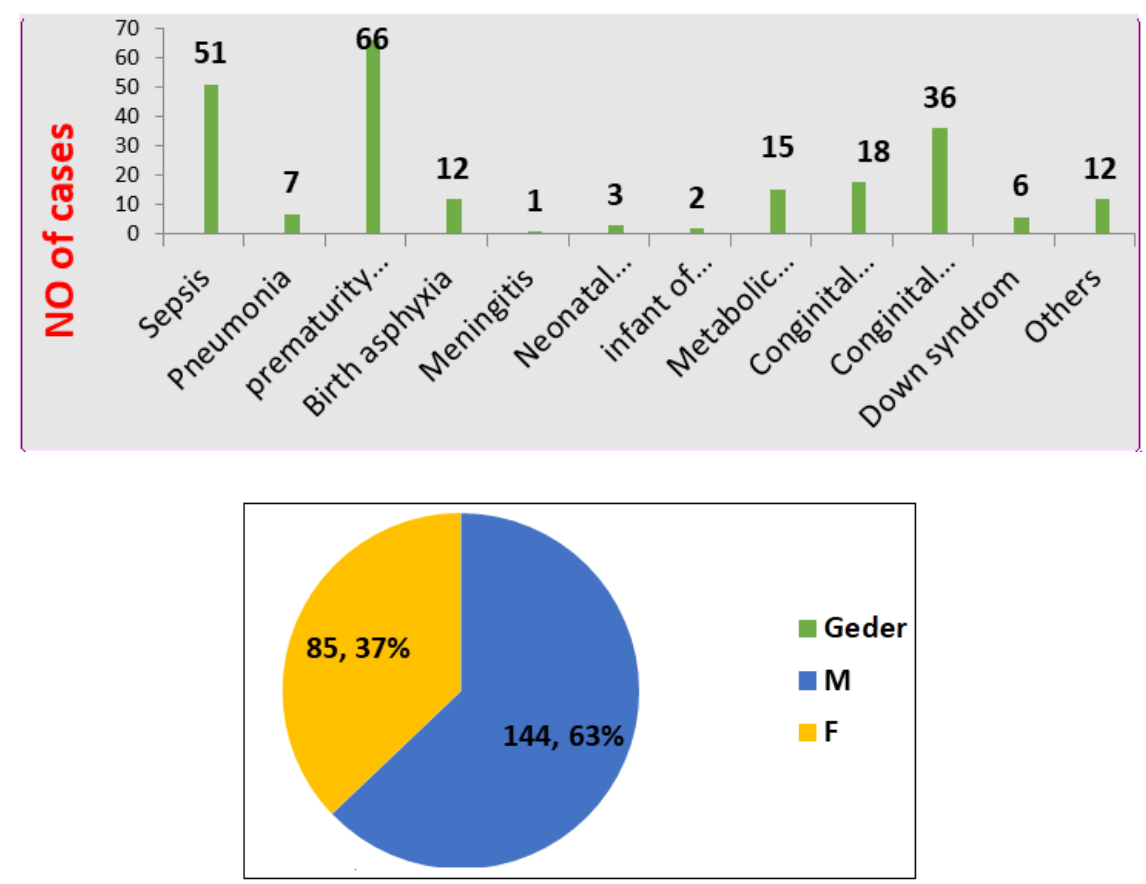

Deaths gender distribution $($ total $=229)$

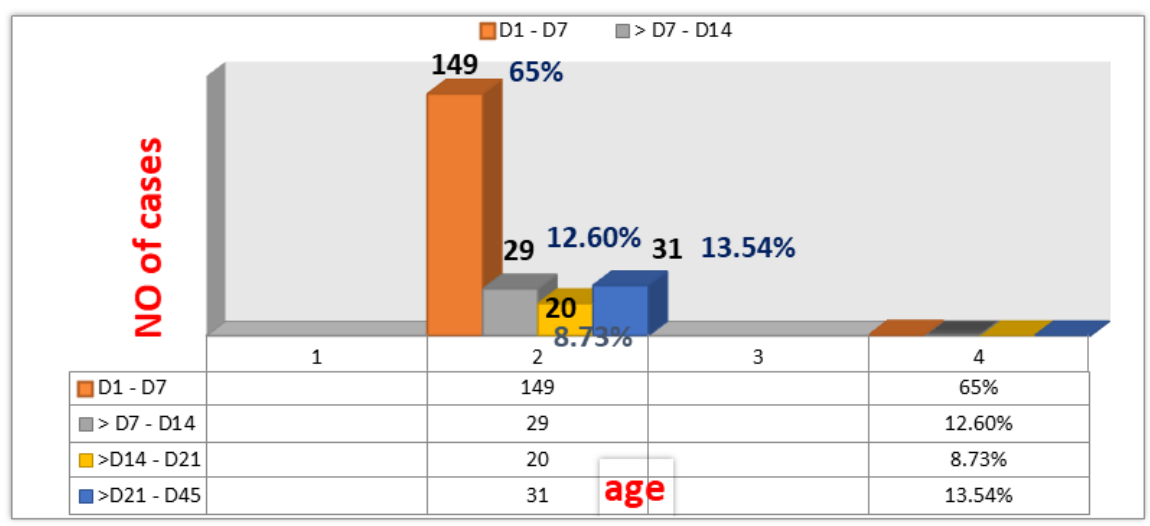

Deaths age distribution

Deaths according to age distribution

\begin{tabular}{|l|l|l|}
\hline AGE & NO of cases & percent \\
\hline D1-1week & 149 & \%65 \\
\hline 1weeks-2weeks & 29 & $\mathbf{1 2 . 6 0 \%}$ \\
\hline 2weeks- weeks & 20 & $\mathbf{8 . 7 3 \%}$ \\
\hline >weeks 3 & 31 & $\mathbf{1 3 . 5 4 \%}$ \\
\hline
\end{tabular}

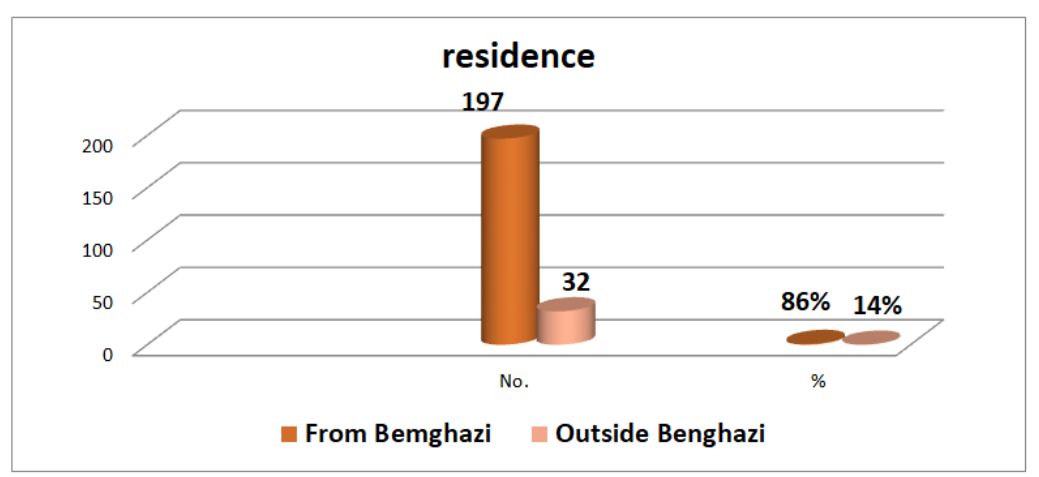

Deaths according area of residence 


\begin{tabular}{|c|c|c|}
\hline \multicolumn{3}{|c|}{ Deaths according to residence } \\
\hline city & NO of cases & percent \\
\hline Benghazi & 197 & $86 \%(12.2 \%)$ \\
\hline Ejdabia & 11 & $4.8 \%(40.7 \%)$ \\
\hline Albeda & 4 & $1.75 \%(40 \%)$ \\
\hline Almaraj & 6 & $2.63 \%(40 \%)$ \\
\hline Seret & 4 & $1.75 \%(66.7 \%)$ \\
\hline Tobrouk & 3 & $1.31 \%(42.9 \%)$ \\
\hline Darna & 2 & $0.88 \%(25 \%)$ \\
\hline alkofra & 2 & $0.88 \%(40 \%)$ \\
\hline Total de & 229 & $100 \%$ \\
\hline
\end{tabular}

\section{Chi-Square Tests}

\begin{tabular}{|c|c|c|c|c|c|}
\hline (2 & Value & df & $\begin{array}{l}\text { Asymp. Sig. } \\
\text { (2-sided) }\end{array}$ & $\begin{array}{l}\text { Exact Sig. (2- } \\
\text { sided) }\end{array}$ & $\begin{array}{l}\text { Exact Sig. (1- } \\
\text { sided) }\end{array}$ \\
\hline Pearson Chi-Square & $2.674^{\mathrm{a}}$ & 1 & .102 & & \\
\hline Continuity Correction ${ }^{b}$ & 2.335 & 1 & .127 & & \\
\hline Likelihood Ratio & 2.679 & 1 & .102 & & \\
\hline Fisher's Exact Test & & & & .109 & .063 \\
\hline $\begin{array}{l}\text { Linear-by-Linear } \\
\text { Association }\end{array}$ & 2.668 & 1 & .102 & & \\
\hline $\mathrm{N}$ of Valid Cases & 457 & & & & \\
\hline \multicolumn{6}{|c|}{ a. 0 cells $(0.0 \%)$ have expected count less than 5 . The minimum expected count is 58.37 . } \\
\hline
\end{tabular}

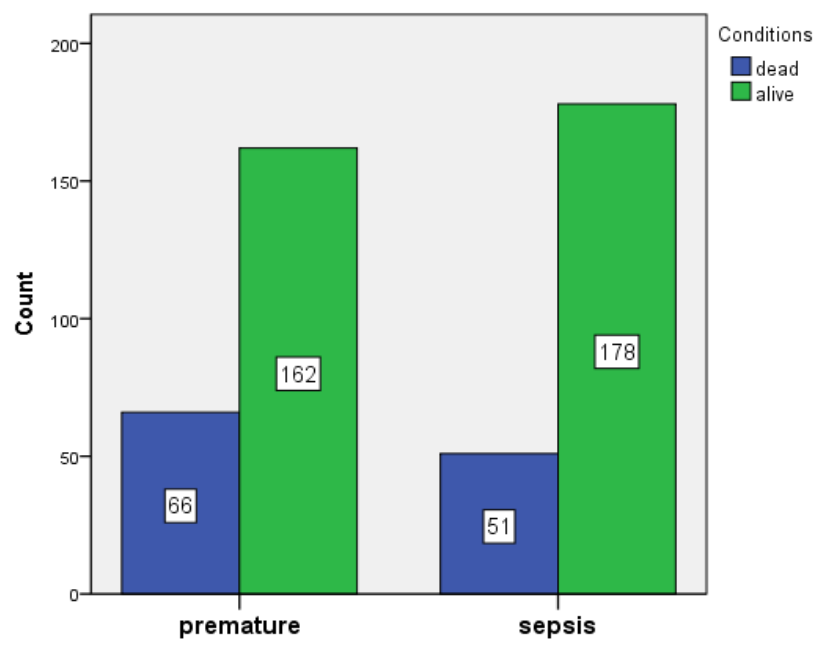

\section{DISCUSSION}

Out of 1720 neonatal admissions to the Benghazi Children Hospital during 2019, there were 229 neonatal deaths (13.3\%). The remaining 1491 $(86.7 \%)$ neonates were discharged after improvement.

In this study, the male gender was predominant in admissions and deaths $62 \%$. Most of admissions and deaths occurred at first week of life $(68 \%$ and $65 \%$ respectively),

The common cause admission at Benghazi Children Hospital were Jaundice followed by prematurity. Whereas Rakesh's study in 2019 revealed that neonatal jaundice, birth asphyxia, and sepsis are the most common causes of admission (Kumar et al., 2019).

The common cause of death is prematurity and related problems $(28.82 \%)$. The neonatal mortality is higher but the causes and other variables are similar to the data reported by a study done on 2015 (Zahra Alharam, Isaada Ali Abdalla Elsaeti, Mohamed Masood et al.,) 12 at neonatal department, Benghazi children hospital, which recorded 1610 newborn admitted to Benghazi neonatal department, deaths was $122(7.5 \%)$ 
Mohamed Masoud Alferjani et al; Sch J App Med Sci, Jan, 2022; 10(1): 114-122

,common causes of deaths is premature $(26.23 \%)$ and $51.6 \%$ of deaths occurred in the first week of life a.

In Tobrouk medical center a study done by Eman altarhoni, Nema alhoni 2018-2019 show results of $16.36 \%$ of neonatal deaths, the main cause of death was prematurity $61.1 \%$ and $57 \%$ of deaths in first week of life.

Anther study done in Misurata general hospital in 2012, in this study the neonatal mortality rate among 6520 newborns was 12 per 1000 live births and the deaths in the SCBU was $10.06 \%$, the majority of deaths $(88 \%)$ occurred during early neonatal period and the common cause of death is prematurity (37.5\%) sepsis $(18 \%)$.

Our study is agreed with a study conducted in Johannesburg, South Africa 2016 were prematurity was the main cause of death $(40 \%)$ and in this study most of the deaths occurred in the first week of life [14].

\section{Conclusions}

1. The study found that the neonatal mortality at Benghazi children hospital is nearly similar to the rates reported in other hospitals in Libya and internationally.

2. Much higher rate of deaths noted in the referred case from privet clinics and other cities.

3. Most of neonates died were premature and within the first 7days of life as reported in the literature.

\section{RECOMMENDATIONS}

- High levels of neonatal care and facilities should be available in all general hospitals and privet clinics

- The transfer ambulances should be provided with portable incubators and portable ventilators and qualified persons

- The other specialties such as pediatric surgery, neurosurgery and ENT should be available in other cities to ovoid complications and delay in managing such cases

- Neonatal screening program should be started for early detection neonatal diseases specially metabolic and inherited diseases.

- Important drugs for neonates such as surfactant and prostaglandinE1 should be available and ready for use in all neonatal care units.

- Nursing staff should be increased in enough numbers (at least one nurse for each 3 neonates) in all NCUs and should be highly qualified for neonatal care

- Sour results proportion of facility-based neonatal deaths was unacceptably high. The main causes of death were preventable and treatable. Hence, improving the timing and quality of antenatal care is essential for early detection, anticipating highrisk newborns, and timely interventions.
Furthermore, tertiary health facilities could lead to a reduction in neonatal death in this setting.

\section{Limitation of the study}

1. The data collected in this study only reflected a percentage of Benghazi Pediatric Hospital cases and not all cities in the country.

2. Important missing information not recorded in medical records was significant in some variables such as birth weight and maturity. Therefore, lack of information on the death certificates creates errors

\section{REFERENCES}

1. UNICEF, WHO WB \& UN. (2018). Levels and Trends in Child Mortality - Report 2018 Estimates developed by the UN inter-agency Group for Child Mortality Estimation [internet]. New York USA: UNICEF; p. 8-48. Available from: https://data.unicef.org/wp-content/uploads/2018.

2. WHO. WHO Child mortality [Internet]. 2016. Available from: http://www.who.int/maternal_child.

3. Oza, S., Lawn, J. E., Hogan, D. R., Mathers, C., \& Cousens, S. N. (2014). Neonatal cause-of-death estimates for the early and late neonatal periods for 194 countries: 2000-2013. Bulletin of the World Health Organization, 93, 19-28.

4. Ali, S. R., Ahmed, S., \& Lohana, H. (2013). Disease patterns and outcomes of neonatal admissions at a secondary care hospital in Pakistan. Sultan Qaboos University Medical Journal, 13(3), 424.

5. UNICEF, WHO, World Bank U-DPD. Levels and trends in child mortality [Internet]. New York; 2015. Available from: http://www.who.int/maternal_child_adolescent/doc uments/levels_trends_http: /levels_trends_child_mortality.

6. Omoigberal, A. I., Sadoh, W. E., \& Nwaneri, D. U. (2010). A 4 year review of neonatal outcome at the University of Benin Teaching Hospital, Benin City. Nigerian Journal of Clinical Practice, 13(3), 321-325.

7. Seoud, I., Rasha, M., El-Din, R. N., Said, R. N., \& Hessin, H. A. (2005). Predictors of neonatal mortality in intensive care unit in children's hospital, Cairo University. Alexandria $J$ Pediatr, 19(1), 93-97.

8. Mekonnen, Y., Tensou, B., Telake, D. S., Degefie, T., \& Bekele, A. (2013). Neonatal mortality in Ethiopia: trends and determinants. BMC public health, 13(1), 1-14.

9. child_mortality9. ICF CSA (CSA) [Ethiopia] and. Ethiopia Demographic and Health Survey 2016. Key Indicators Report. Addis Ababa, Ethiopia, and Rockville Maryland, USA: CSA and ICF; 2016.

10. WHO. WHO Newborn death and illness [Internet]. Geneva 27, Switzerland: WHO Press, World 
Mohamed Masoud Alferjani et al; Sch J App Med Sci, Jan, 2022; 10(1): 114-122

Health Organization; 2011. Available from: http://www.who.int/pmnch/media/press.

11. World Bank. Ethiopia Neonatal mortality rate, World Development Indicators, The World Bank 1960-2017 [Internet]. 2018. Available from: https://knoema.com/atlas/Ethiopia/Neonatalmortality-rate.

12. Weldearegawi, B., Melaku, Y. A., Abera, S. F., Ashebir, Y., Haile, F., Mulugeta, A., ... \& Spigt, M. (2015). Infant mortality and causes of infant deaths in rural Ethiopia: a population-based cohort of 3684 births. BMC public health, 15(1), 1-7.

13. Babaei, H., \& Dehghan, M. (2018). Study of causes of neonatal mortality and its related factors in the neonatal intensive care unit of Imam Reza hospital in Kermanshah, Iran during (20142016). International Journal of Pediatrics, 6(5), 7641-7649.

14. Saharia, P. K., Kalita, B., Bhuyan, S., Hussain, I. A., Pokhral, H., Bhagabati, S. K., ... \& Sharma, R. (2019). Economic impact of bacterial disease caused by motile Aeromonas (MAS) in carp culture practices of assam, India: An analysis.

15. Moundzika-Kibamba, J. C., \& Nakwa, F. L. (2018). Neonatal mortality at Leratong Hospital. South African Journal of Child Health, 12(1), 24-28. 